\title{
Response to Haddon and Hutchinson: Empathy in Ensemble Performance
}

\author{
MINE DOĞANTAN-DACK \\ University of Oxford, UK
}

\begin{abstract}
This commentary emphasizes empathy as a biologically and culturally embedded, dynamically emergent phenomenon, and critically evaluates its epistemic status in explaining human action.
\end{abstract}

Submitted: 2014 October 14; accepted: 2014 November 3.

KEYWORDS: piano duet, empathy as emergent, empathy as epistemic tool

AS the site of musical and social skills, chamber ensemble performance offers researchers rich data about complex expressive and communicative processes that shape the practices of musicians working together in groups. To date, most of the research in this area has focused on the practice of string quartets, (e.g. Murnighan \& Conlon, 1991; Davidson \& Good, 2002; King, 2006), and several studies explored smaller groups, including voice-piano (Ginsborg \& King, 2007), flute-clarinet (Davidson, 2012), and piano duos (Blank \& Davidson, 2007). Little work has been done, however, to explore the workings of the piano duet, i.e. two pianists at one piano (Williamon \& Davidson, 2002). The article titled "Empathy in Piano Duet Rehearsal and Performance" by Elizabeth Haddon and Mark Hutchinson is, therefore, a timely contribution to this under-researched area. I particularly welcome the emphasis their article puts on the inherently social nature of music making, which can be easily forgotten in the solitary environment of the practice room. Pianists in particular are vulnerable to the negative (musical) consequences of nonsocial work patterns, since many educational institutions do not require them to engage in ensemble practice from an early stage and they come to chamber music relatively late —if at all—compared to other instrumentalists. "Empathy in Piano Duet Rehearsal and Performance" is especially valuable in reminding pianists of the kinds of musical and social skills that can be learned and nourished in ensemble contexts.

Haddon and Hutchinson's research aims to extend our "understanding of empathy in relation to musical partnership" by exploring empathic processes between two pianists in the context of a piano duet. In this commentary, I would like to emphasize three issues in relation to empathy that are fundamental for their research, but are not clarified or discussed in the article. These are: 1) empathy as a biologically and culturally embedded phenomenon; 2) empathy as a dynamically emergent experience; and 3) the epistemic status of empathy in explaining human actions. But first, a note of caution is in order: as the authors also note, there is no consensus in the research literature on the definition of empathy. The term "is currently applied to more than a half-dozen phenomena... [each referring to] a conceptually distinct, stand alone psychological state. Further, each of these states has been called by names other than empathy. Opportunities for disagreement abound." (Batson, 2009, p. 3). Since Haddon and Hutchinson do not provide their own definition of the term, "empathy" becomes a free-floating umbrella notion applied to a variety of phenomena, which can easily be identified using other concepts and terms - such as "understanding," "sympathy," "communication," and so on. Broadly speaking, these and similar terms can all be used to refer to the ability to participate, in some form and measure, in another's feelings and thoughts. My aim here is not to argue for one or the other definition of empathy as having stronger explanatory power; for the purposes of this commentary, I shall use the term "empathy" to refer to a certain intersubjectively motivated experience marked by affective-and at times cognitive and motorattunement, all the while noting that one can put forward convincing arguments for the employment of another term or concept to account for such experiences. In their article, Haddon and Hutchinson put forward the piano duet medium as specifically relevant for addressing questions of empathy within musical performance. The distinctiveness (or not) of the piano duet context in relation to empathy could be better understood had the authors set it in relief against a broader biological-cultural background by briefly discussing empathy as a fundamental intersubjective human response (de Waal, 2009a, 2009b); as a basic 
process in any kind of creative collaboration driven by a commitment to a common goal that transcends personal interests (Reynolds \& Reason, 2012; Krznaric 2014); and as a crucial factor in group musicking in general (Cross et al., 2012). Any characteristics of the piano duet medium that render it more conducive to the emergence of empathic processes would need to be discussed and evaluated against this wider background, within which ensemble musicians are necessarily embedded.

The narrative account given by Haddon and Hutchinson of their collaborative project presents a view of empathy as a more or less fixed capacity; it is built on the assumption that ensemble musicians possess a capacity or skill called "empathy," and that they each have brought such a capacity to their project from the beginning. Research indicates, however, that empathy is not something we either have or lack (Laurence, 2008), and that it is a phenomenon that is rather cultivated through processes of socialization, as we interact with the members of our species in various cultural contexts (Handel, 2006). Furthermore, it is a process that can have differing stages, marked by the emergence of increasingly or decreasingly empathic responses. In this sense, the narrative account given by Haddon and Hutchinson would have been more accurate had they discussed empathy as a dynamic, emergent, ongoing temporal process, cultivated before, during, and after the project-related activities. For instance, it is relevant for the emergence of empathic processes during the project that Haddon and Hutchinson had known each other and worked together as musicians prior to this undertaking - albeit in a teacher-student context. Their personal artistic histories as pianists are also relevant in allowing them to share, to a high degree, some situated knowledge regarding instrumental expertise. Given that humans employ their own knowledge basis when evaluating the internal states of others (Nickerson et al., 2009), the availability of this kind of highly specialized, expert knowledge among collaborating partners facilitates the emergence of empathic responses - a point not discussed in the article. It is, therefore, highly likely that the empathic resonances they had already built in their previous teacher-student roles, and the common artistic knowledge background they brought with them to the piano duet context, were further nourished, developed, and extended during this project.

Haddon and Hutchinson's narrative also presents empathy as the cause or explanans of various phenomena they identify in analyzing their shared reflective diary: empathy is put forward as a cloak for all that is positive in their interaction, and rendered an epistemic tool that yields knowledge about why certain processes unfolded in a certain manner. For instance, fluidity of roles throughout the rehearsal process, construction of shared concerns, articulation of differences, devising positive ways of discussing and resolving potential issues of divergence, etc. are all attributed to empathy. Yet, it is entirely plausible that the causal connection the authors assume between empathy and these phenomena work in the reverse direction: in other words, it is possible that construction of shared concerns, for example, begets empathic responses; that articulation of differences leads to empathy; that the musical interaction in a piano duet context facilitates the emergence of empathy, rather than empathy functioning as a facilitative tool, etc. This possibility is not explored by Haddon and Hutchinson, and the narrative account they provide does not demonstrate with sufficient evidence the functioning of empathy, but rather assumes it. I, for one, can imagine a meaningful alternative narration of the findings of their project that stipulates a causal connection in the reverse direction, by portraying their particular collaborative undertaking as the cause of emergent empathic processes.

In spite of these conceptual and methodological issues that need clarification, the implications of Haddon and Hutchinson's article for music pedagogy are highly important and should be further explored. As the authors also note, performance pedagogy can at times be an authoritarian practice that intimidates and frustrates aspiring musicians and suppresses their creativity; it is, therefore, vital to propose and implement alternative pedagogical environments that nourish empathic relationships, which are "in direct contrast to the power relationship ... non-manipulative [and] co-operative" and engender "interpersonal harmony and personal knowing of the other, enhances the other, and fosters acceptance and tolerance of difference" (Laurence, 2009). In this connection, Haddon and Hutchinson can fruitfully develop their research to propose strategies for enhancing empathy in ensemble rehearsal and performance.

\section{REFERENCES}

Batson, C. D. (2009). These things called empathy: Eight related but distinct phenomena. In J. Decety \& W. Ickes (Eds.), The social neuroscience of empathy (pp. 3-16). Cambridge, MA: MIT Press. 
Blank, M., \& Davidson, J. W. (2007). An exploration of the effects of musical and social factors in piano duo collaborations. Psychology of Music, 35(2), 231-248.

Cross, I., Laurence, F., \& Rabinowitch, T. (2012). Empathy and creativity in group musical practices: Towards a concept of emphatic creativity. In G. E. McPherson \& G. Welch (Eds.), The Oxford handbook of music education, vol. 2 (pp. 337-353). Oxford: Oxford University Press.

Davidson, J. W. (2012). Bodily movement and facial actions in expressive musical performance by solo and duo instrumentalists: Two distinctive case studies. Psychology of Music, 40(5), 595-633.

Davidson J. W., \& Good J. J. (2002). Social and musical co-ordination between members of a string quartet: An exploratory study. Psychology of Music, 30(2), 186-201.

de Waal, F. (2009a). Primates and philosophers: How morality evolved. Princeton: Princeton University Press.

de Waal, F. (2009b). The age of empathy: Nature's lessons for a kinder society. New York: Harmony Books.

Ginsborg, J., \& King, E. C. (2007). The roles of expertise and partnership in collaborative rehearsal. In A. Williamon \& D. Coimbra (Eds.), Proceedings of the International Symposium on Performance Science, 2007 (pp. 61-66). Utrecht: AEC.

Handel, G. (Ed.) (2006). Childhood socialization. Rutgers: Aldine Transaction.

King E. C. (2006). The roles of student musicians in quartet rehearsals. Psychology of Music, 34(2), $262-$ 282.

Krznaric, R. (2014). Empathy: A handbook for revolution. Croydon: Random House.

Laurence, F. (2008). Music and empathy. In O. Urbain (Ed.), Music and conflict transformation (pp. 1325). London: I.B. Tairus.

Laurence, F. (2009). Music, empathy and intercultural understanding. Retrieved from http://www.slideshare.net/WAAE/music-empathy-and-intercultural-understanding-felicity-laurence

Murnighan, J. K., \& Conlon, D. E. (1991). The dynamics of intense work groups: A study of British string quartets. Administrative Science Quarterly, 36, 165-186.

Nickerson, R. S., Butler, S. F., \& Carlin, M. (2009). Empathy and knowledge projection. In J. Decety \& W. Ickes (Eds.), The social neuroscience of empathy (pp. 43-56). Cambridge, MA: MIT Press.

Reynolds, D., \& Reason, M. (2012). Kinesthetic empathy in creative and cultural practices. Chicago: The University of Chicago Press.

Williamon, A., \& Davidson, J. W. (2002). Exploring co-performer communication. Musicae Scientiae, $6(1), 53-72$. 